University of Nebraska - Lincoln

DigitalCommons@University of Nebraska - Lincoln

\title{
A comparison of internal and external lipids of nondiapausing and diapause initiation phase adult Colorado potato beetles, Leptinotarsa decemlineata
}

\author{
George D. Yocum \\ USDA-ARS Red River Valley Agricultural Research Center, george.yocum@ars.usda.gov \\ James S. Buckner \\ USDA-ARS Red River Valley Agricultural Research Center \\ Charlotte L. Fatland \\ USDA-ARS Red River Valley Agricultural Research Center
}

Follow this and additional works at: https://digitalcommons.unl.edu/usdaarsfacpub

Part of the Agricultural Science Commons

\begin{abstract}
Yocum, George D.; Buckner, James S.; and Fatland, Charlotte L., "A comparison of internal and external lipids of nondiapausing and diapause initiation phase adult Colorado potato beetles, Leptinotarsa decemlineata" (2011). Publications from USDA-ARS / UNL Faculty. 888.

https://digitalcommons.unl.edu/usdaarsfacpub/888
\end{abstract}

This Article is brought to you for free and open access by the U.S. Department of Agriculture: Agricultural Research Service, Lincoln, Nebraska at DigitalCommons@University of Nebraska - Lincoln. It has been accepted for inclusion in Publications from USDA-ARS / UNL Faculty by an authorized administrator of DigitalCommons@University of Nebraska - Lincoln. 


\title{
A comparison of internal and external lipids of nondiapausing and diapause initiation phase adult Colorado potato beetles, Leptinotarsa decemlineata
}

\author{
George D. Yocum*, James S. Buckner, Charlotte L. Fatland \\ USDA-ARS Red River Valley Agricultural Research Center, Biosciences Research Laboratory, 1605 Albrecht Boulevard, Fargo, ND 58102-2765, USA
}

\section{A R T I C L E I N F O}

\section{Article history:}

Received 12 January 2011

Received in revised form 31 March 2011

Accepted 31 March 2011

Available online 7 April 2011

\section{Keywords:}

Insect diapause

Storage lipids

Cuticular lipids

Triacylglycerol

Methyl-branched alkanes

\begin{abstract}
A B S T R A C T
The Colorado potato beetle, Leptinotarsa decemlineata, reared under diapause-inducing conditions will emerge from the soil as an adult and enter the diapause initiation phase, a period where metabolic reserves are stockpiled before the beetles enter the nonfeeding diapause maintenance phase. Internal and external lipids were characterized during the diapause initiation phase (IP) and compared to the lipid profiles of nondiapausing adults. The primary internal lipids of both diapause IP and nondiapausing adults are triacylglycerols. Only trace amounts of internal lipids were detected in day 1 diapause IP adults. A dramatic increase in internal lipids was observed between day 7 and day 15 post-emergence in the diapause IP adults. The majority of the triacylglycerol isomers were identified as C50, C52 and C54 chain lengths by GC-MS. There were no observed differences in the isomeric distribution of the major internal lipids between diapause IP and nondiapausing adults. External lipids were mainly methyl-branched alkanes containing a 25 to 53 carbon backbone. The quantity of external lipids increased from day 1 to day 7 post-emergence in both the diapause IP and nondiapausing adults, with the bulk of the increase occurring in the longer chain-length methylalkanes.
\end{abstract}

Published by Elsevier Inc.

\section{Introduction}

The Colorado potato beetle (CPB), Leptinotarsa decemlineata (Say), is believed to have originated in southern Mexico and experienced a rapid range expansion beginning in the mid-1800s (Tower, 1906). L. decemlineata is now endemic in most of the potato growing regions in the northern hemisphere and is the major defoliator of potato in those regions (Gauthier et al., 1981; Ferro, 1985; Weber and Ferro, 1994; EPPO, 2006). Because of its status as the main insect pest of potato, the $\mathrm{CPB}$ has been extensively investigated for over a hundred years. The CPB is also notorious for being the first pest insect against which insecticide was widely used, thereby setting the stage for the adoption of insecticides as the preferred means of insect control (Tower, 1906, 1918; Casagrande, 1985, 1987; de Kort, 1990; Clark, 2007).

In order for the $\mathrm{CPB}$ or any insect species to colonize a new region it must be able to synchronize its life cycle to the abiotic and biotic factors required for reproduction and development. Diapause, a physiological dormancy, is the chief mechanism by which insects achieve this match with their environment. As such, diapause is a major component controlling insect seasonal phenology (Tauber et al., 1986; Danks, 1987). Diapause is a dynamic physiological process in which the individual insect goes through a series of distinct

\footnotetext{
* Corresponding author. Tel.: +1 701239 1301; fax: +1 7012391348 E-mail address: george.yocum@ars.usda.gov (G.D. Yocum).
}

physiological stages (Koštál, 2006) prior to the onset of adverse environmental conditions. In CPB reared under laboratory diapauseinducing conditions, the adult beetle will emerge from the soil and enter the diapause initiation phase (IP), a period of intense feeding, high metabolic rates and a specific sequence of gene expression. By day 15 post-emergence, the beetles enter the diapause maintenance phase (MP), feeding has stopped, and metabolic rates are low and by day 20 the digestive genes are downregulated (Yocum et al., 2009a). One of the key physiological characteristics of the diapause IP is the accumulation of metabolic reserves that will enable the beetles to bridge the period of adverse conditions.

Lipids are the primary metabolic reserves that insects use during diapause (Hahn and Denlinger, 2007). Internal lipids contain high stored energy values and their metabolism generates metabolic water. Diapause is a period of restricted water uptake for most insects, and the metabolic water generated from lipids may aid in survival (Wharton, 1985; Danks, 2000). In the CPB at the time of adult emergence from the soil, the lipids are approximately $8 \%$ of the dry weight of the adult beetle (Fink, 1925) and, following a period of active feeding, the lipid fraction increases to about $29 \%$ by the time the beetle enters the soil to diapause. The early non-English literature on lipids in diapausing CPB was summarized by Petrova (1976). In these studies the lipid fraction of the total body dry weight varied from 23 to $44 \%$ at the beginning of diapause. The major decline in the lipid reserves occurred during autumn prior to the onset of low winter temperatures, and also around the time of emergence from the soil in spring. During the course of diapause development, lipid utilization varies, but the hemolymph titers remain constant (Lefevere et al., 
1989). Besides their role as metabolic reserves lipids are critical components of insect cuticle forming a barrier preventing water loss. The lipid layer of the cuticle is normally thicker in diapausing insects as compared to their nondiapause counterparts helping them to conserve water during a time of restricted water uptake (Danks, 1987; Buckner, 1993; Danks, 2000). Most of the above studies were concerned with the overall amount of lipids associated with diapause development and not the physical characterization and classification of the lipids. However, the type of lipids may be as important, if not more important, than the absolute amount of lipids for the successful completion of diapause. The chemical characterization and classification of the lipids in the CPB have only been recently carried out, but that study was restricted to eggs and nondiapausing adults (Nelson et al., 2003). The objectives of this investigation are twofold: 1) determine the chemical composition of the internal lipids during the diapause IP and early MP; and 2) characterize external (cuticular) lipids from IP and early MP adults. Comparisons were made with the internal and external lipids of nondiapausing CPB adults.

\section{Material and methods}

\subsection{Insects}

$\mathrm{CPB}$ adults were obtained from the colony maintained at the Red River Valley Agricultural Research Center, USDA-ARS, Fargo, ND, USA. Larvae were fed potato (Solanum tuberosum L. 'Luther Burbank') plants. Diapause IP and early MP adults were obtained by rearing larvae and pupae at $8 \mathrm{~h}$ light: $16 \mathrm{~h}$ dark, $24 \pm 2{ }^{\circ} \mathrm{C}$ and $65 \%$ relative humidity. The emerged adults were transferred from the emergence cage to $10 \times 10 \times 21 \mathrm{~cm}$ plastic containers, provided potato leaf bouquets held in water bottles and maintained under diapauseinducing conditions. To obtain nondiapausing adults, larvae and pupae were maintained at $16 \mathrm{~h}$ light: $8 \mathrm{~h}$ dark, $24 \pm 2{ }^{\circ} \mathrm{C}$ and $65 \%$ relative humidity. Emerged adults were reared as above except that they were held under nondiapause-inducing conditions. Samples were collected 1, 4, 7 and 15 days post-emergence for diapausing and 1, 4, and 7 days post-emergence for nondiapausing adults. Samples were not obtained from nondiapausing adults at 15 days post-emergence because those CPB adults were actively engaged in ovipositioning. The beetles used in this investigation were not sexed. Adults were weighed, each placed into a $15-\mathrm{mL}$ glass vial that had been pre-rinsed with chloroform $\left(\mathrm{CHCl}_{3}\right)$ and stored $1-2$ days at $-80{ }^{\circ} \mathrm{C}$.

\subsection{Lipid extraction procedures}

$\mathrm{CPB}$ adults were removed from storage at $-80^{\circ} \mathrm{C}$ and warmed to room temperature. Five milliliters of hexane was added to each vial which was stirred gently by hand for $2 \mathrm{~min}$. The hexane was filtered through glass wool. Each adult was then suspended in $5 \mathrm{~mL} \mathrm{CHCl}$ for $45 \mathrm{~s}$ and the solvent extract filtered through glass wool. The hexane and $\mathrm{CHCl}_{3}$ extracts for each adult were combined, the solvent was evaporated under a stream of nitrogen with mild heating, and the dried residue stored at $-20^{\circ} \mathrm{C}$. Following removal of the cuticular lipids, each adult was placed in a $15-\mathrm{mL}$ glass tissue grinder and homogenized with $5 \mathrm{~mL}$ of $\mathrm{CHCl}_{3}$ for extraction of the internal lipids. Each homogenate was filtered through glass wool. The filtrates were reduced to $0.1-0.2 \mathrm{~mL}$ with nitrogen gas and mild heating, and internal lipid residues were stored at $-20{ }^{\circ} \mathrm{C}$.

\subsection{Gas chromatography-mass spectrometry (GC-MS) analysis}

GC-mass spectrometry (MS) was performed on a Hewlett Packard Model 5890A gas chromatograph equipped with a temperature- and pressure-programmable on-column injector (Agilent Technologies, Palo Alto, California) and a $1 \mathrm{~m}$ retention gap, connected to a J\&W Scientific DB-1MS capillary column $(0.2 \mathrm{~mm} \times 12.5 \mathrm{~m}, 0.33 \mu \mathrm{m}$ phase thickness) (Folson, California) and coupled to an HP 5970B quadrupole mass selective detector (Agilent Technologies, Palo Alto, California). The injector temperature was set at $153^{\circ} \mathrm{C}$, the ion source was set at $70 \mathrm{eV}$ and the detector temperature was $300^{\circ} \mathrm{C}$. The helium carrier gas flow was a constant $0.75 \mathrm{~mL} / \mathrm{min}$. The injection volume was $1 \mu \mathrm{L}$ and the samples were dissolved in $\mathrm{CHCl}_{3}$. For analysis of $\mathrm{CPB}$ adult cuticular lipids, the column temperature was initially held at $150{ }^{\circ} \mathrm{C}$ for $4 \mathrm{~min}$, programmed to $320^{\circ} \mathrm{C}$ at $4{ }^{\circ} \mathrm{C} / \mathrm{min}$ and held at $320^{\circ} \mathrm{C}$ until all observable peaks were eluted. The column temperature program for analysis of internal lipids was $150{ }^{\circ} \mathrm{C}$ for $4 \mathrm{~min}$, programmed to $335{ }^{\circ} \mathrm{C}$ at $4{ }^{\circ} \mathrm{C} / \mathrm{min}$ where it was held until all observable peaks were eluted: an additional $55 \mathrm{~min}$ at $335^{\circ} \mathrm{C}$.

The identity of individual fatty acid constituents of TAGs was derived from GC-MS analyses as previously described (Buckner et al., 2004; Chirumamilla et al., 2010). TAG components were structurally identified by interpretation of their electron ionization mass spectra. Diagnostic ions included the molecular ion, the diacylglyceride ions (resulting from the loss of one fatty acid), and the monoglyceride ions and acyl ions for each fatty acid constituent. Diagnostic ions for diacylglycerols included the M-18 ion (loss of water), and the monoglyceride ions (resulting from the loss of one fatty acid) and acyl ions for each fatty acid constituent. Many of the peaks in the TAG fraction contained one or more TAGs and a single mass spectrum contained diagnostic ions for more than one TAG.

Structures of methyl-branched alkanes in the CPB cuticular lipids were deduced from GC-MS retention times and changing fragmentation patterns across individual peaks of electron impact mass spectra. Our findings were consistent with our laboratory's previously reported results for nondiapausing CPB adult cuticular lipid composition (Nelson et al., 2003) that, in addition to retention times and fragmentation data, also used retention indices (Kováts Indices) for methyl-branched alkane identification (Carlson et al., 1998; Nelson et al., 2003). For quantification, the GC-MS total ion current data were analyzed using a three-component standard curve using a mixture of seven authentic standards (listed in order of elution from the capillary GC column): two fatty acid methyl esters (methyl septadecaoate and methyl eicosanoate), a methyl-branched alkane (3-methyl tricosane), an acetate ester (tricosanyl acetate), two alkanes (octacosane and tetracontane), and a wax ester (tricosanyl heptadecanoate). The dose response from 0 to $6.25 \mathrm{ng}$ was linear, polynomial from 6.25 to $100 \mathrm{ng}$ and then linear above $100 \mathrm{ng}$. The conversions of total ion peak area to ng for each component using standard curve formulas were determined as previously described (Nelson et al., 2003).

\section{Results}

\subsection{Internal lipids of diapause IP and early MP adults}

GC-MS analyses of internal lipid extracts of CPB adults, 15 days after adult emergence, revealed major quantities of triacylglycerols (TAGs) and lesser amounts of diacylglycerols and hydrocarbons (Fig. 1B). Only trace amounts of internal lipids were observed for adults 1 day after adult emergence (Fig. 1A). The quantities of TAGs increased dramatically from 1 to 15 days after emergence (Fig. 2). There were measurable levels of TAGs in day 1 adults $(0.01 \mathrm{mg} / \mathrm{adult})$, and average values of 0.26 and $1.46 \mathrm{mg}$ /adult for day 4 and day 7 adults, respectively. The average value of $9.07 \mathrm{mg} /$ adult for day 15 adults was approximately 6 -fold higher than the day 7 average value. This amount of TAGs for day 15 early diapause MP adults represented $6.7 \%$ of the fresh weight. As shown in Fig. 1B, the majority of the TAG isomers separated into three major GC-MS peaks, which consisted of C50, C52 and C54 total acyl carbons. The major C52 peak consisted of TAG isomers with one 16:0 and two C18 acids (either 18:0, 18:1, 18:2 or 18:3). The C54 and C50 peaks consisted of TAG isomers with three C18 acids (either 18:0, 18:1, 18:2 or 18:3) and two C16 acids (16:0) 


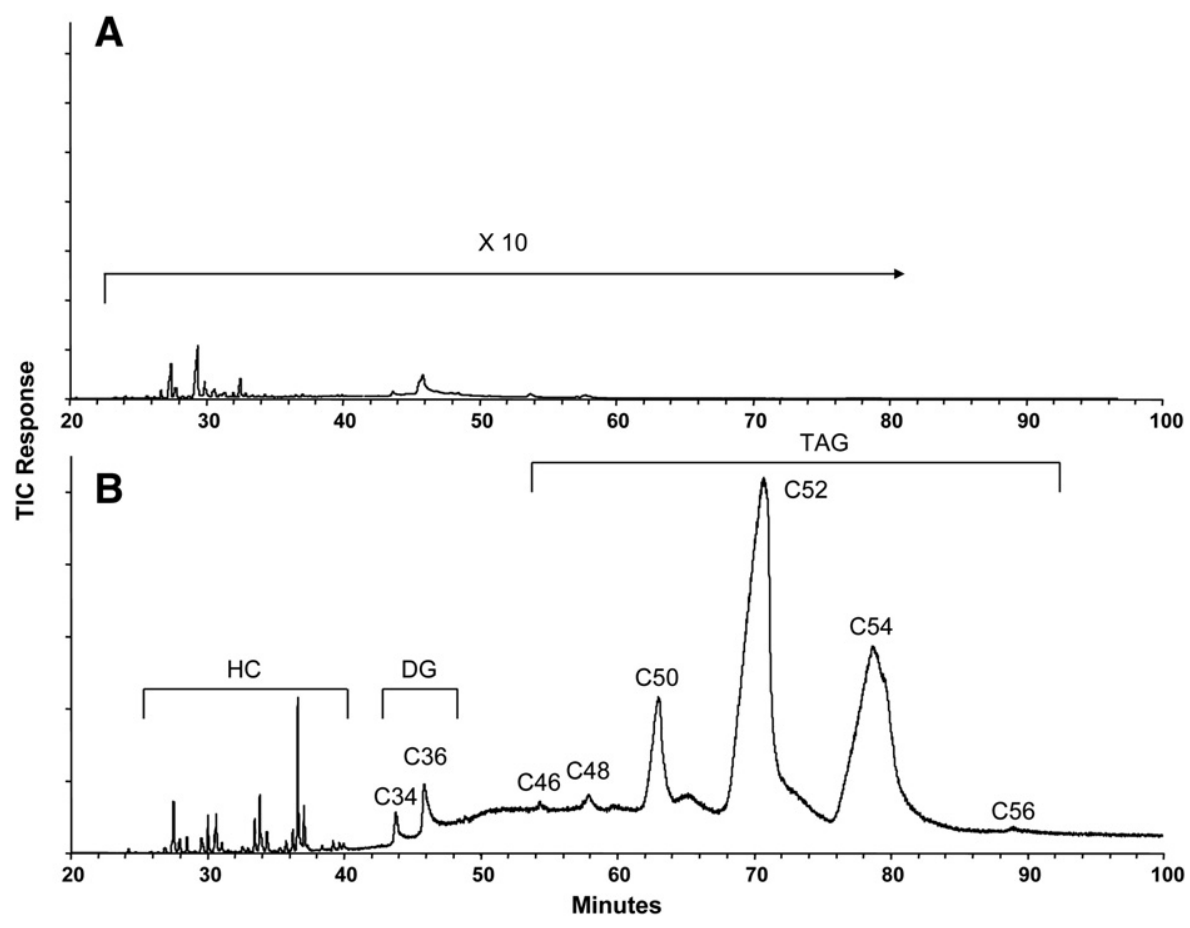

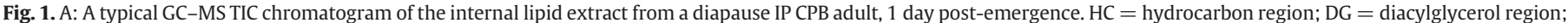

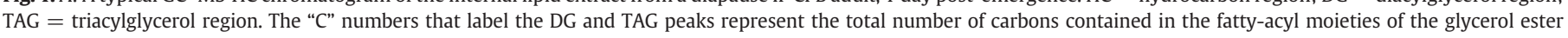

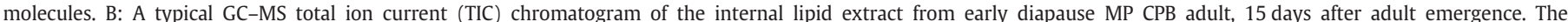

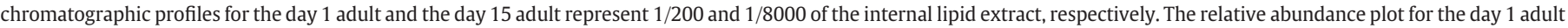
has been expanded 10 -fold.

and one C18 acid (18:0,18:1, 18:2 or 18:3), respectively. Generally, the distributions were the same for the three major TAG groups (as GC-MS peaks) for the 4, 7, and 15 day old adults: the major peak was always TAGs with 52 total carbons, followed by 54 , and 50 , in decreasing order of abundance, and minor amounts of C40-C48 and C56 TAGs (Fig. 3). As shown by the percentage distribution for day 7 diapausing adults (Table 1), the GC-MS resolved TAGs also included small quantities of TAGs with odd total carbon numbers (C45 through C55). These compounds result from the presence of an odd carbon number fatty acid moiety (usually either $15: 0$ or $17: 0$ ).

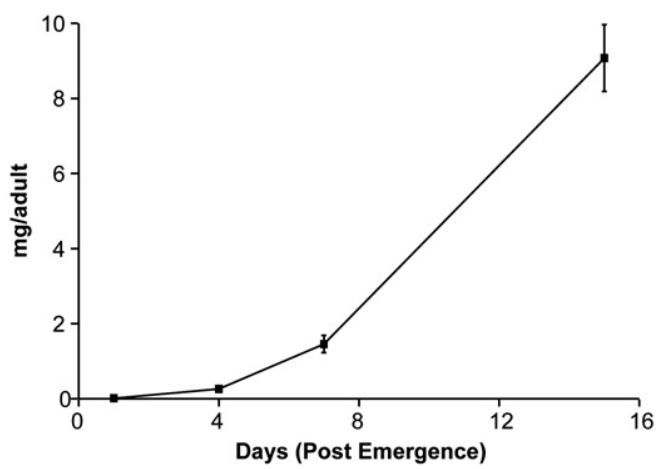

Fig. 2. Quantities of triacylglycerols (TAG) within diapause IP and early diapause MP adult $\mathrm{CPB}$ at days $1,4,7$ and 15 post-emergence. Data points indicate mean values (mg/ adult; $n=5$ ) and standard deviation (SD) is indicated by the error bars. For days 1 and 4 , the heights of the error bars were less than the data points. Quantities were determined by summing the total ion current (TIC) peak areas for TAGs in the GC-MS analysis of total internal lipids for individual adults. Conversions of peak areas to $\mathrm{mg}$ quantities were made by using slope data for increasing amounts of authentic TAG standards.

\subsection{Internal lipids of nondiapausing adults}

For comparison with the internal lipids of diapause IP CPB, lipid extracts from nondiapausing $\mathrm{CPB}, 1,4$, and 7 days after emergence were analyzed by GC-MS. TAGs were the major lipid class (data not shown) and their levels were very low in day 1 adults, but steadily increased by day 7 to an average value of $2.3 \mathrm{mg}$ /adult. As shown in Table 1, the distributions of the three major TAGs for non-diapause day 7 adults as compared to diapause IP day 7 adults were very similar, i.e., the major TAGs were C52, C54 and C50, in decreasing order of abundance. Prominent differences between non-diapause and diapause were the larger percentage composition values for the odd total carbon number C51, C53 and C55 TAGs of non-diapause adults. Similar to the diapause adults, the non-diapause C51 and C53 TAGs result from the presence of either 15:0 or 17:0 single fatty acid moiety and the presence of a 19:0 fatty acid moiety for the C55 TAGs.

\subsection{Cuticular lipids of diapause IP and early MP adults}

The cuticular lipid extracts of diapause IP and early MP adults at 1 , 4,7 and 15 days after adult emergence consisted of only hydrocarbons. The hydrocarbons were mainly a series of C-25 to 53 methyl-branched alkanes (Fig. 4A, B, and C and Table 2). In all analyses, $n$-alkanes (C25C30) were present only in very small quantities. As previously described by Nelson et al. (2003), a short-hand designation was used to describe the methylalkanes: the letters A, B, C and D indicate 1, 2, 3 or 4 methyl branches, respectively. A letter with a prime symbol indicates that the first methyl branch is on a carbon near the end of the carbon chain backbone, i.e. on carbon 2 or 3 . For the hydrocarbons from day 1 adults (Fig. 4A), the major hydrocarbons were the 2,x-dimethylalkanes (Table 2). The most prominent GC-MS components (peaks 15 and 16 ) were a slightly resolved mixture of the $28 \mathrm{~B}^{\prime}$ dimethylalkanes, 2,17- and 2,6-dimethyloctacosane (22.8\% and $11.5 \%$, 


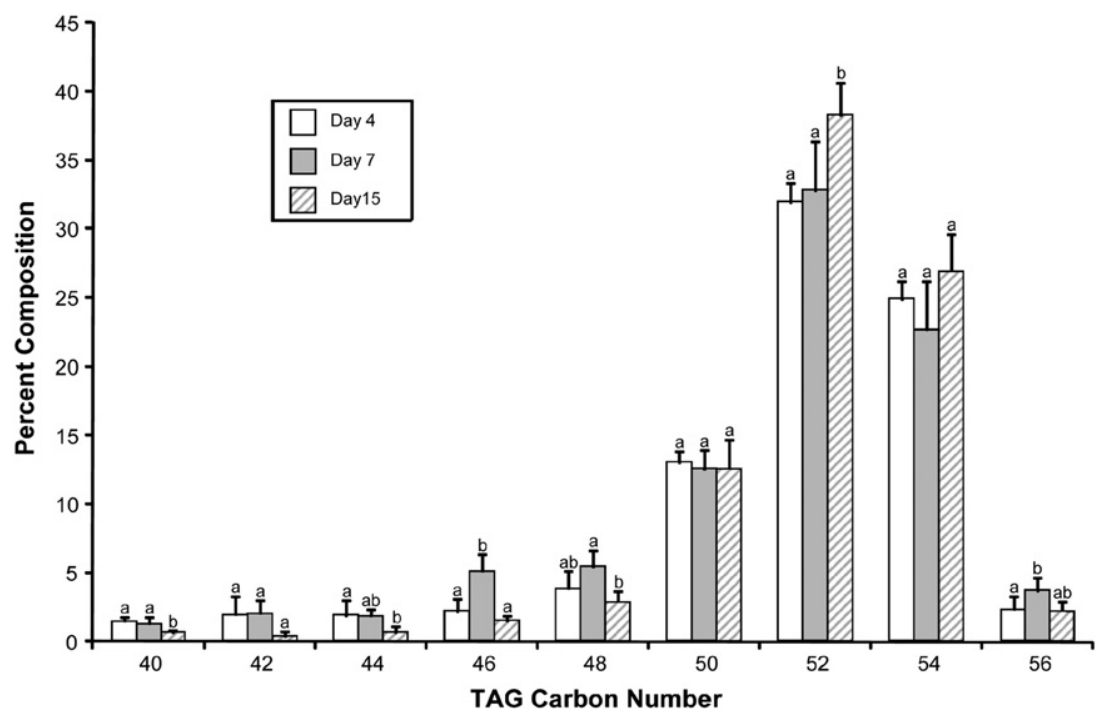

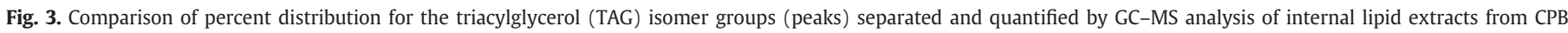

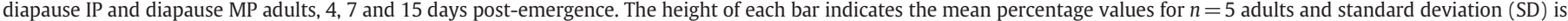
indicated by the error bars. Bars with the same letters are not significantly different (one way ANOVA, $P>0.05$ ).

respectively). Another major peak consisted of a mixture of the $28 \mathrm{C}^{\prime}$ trimethylalkanes, i.e. 2,10,18- and 2,10,16-trimethyloctacosanes (9.0\%). Other prominent components constituting 5-6\% of the day 1 methylalkanes were: 28A', 2-methyloctacosane; 29A, 11-methylnonacosane; $30 \mathrm{~A}^{\prime}$, 3-methyltriacontane; and $30 \mathrm{~B}^{\prime}$, a mixture of 2,12- and 2,10dimethyltriacontanes (Table 2).

When compared to the hydrocarbons from day 1 diapause IP adult, day 4 diapause IP adults showed increased quantities of lipid arising mainly from the appearance of longer chain-length C32-C37 methylbranched alkanes (Table 2). In addition to the relative amounts of C28 and C30 methylalkanes as determined for day 1 adults (Fig. 4A), the hydrocarbon chromatograms for day 4 adults showed prominent peaks for the trimethylalkanes $\left(32 \mathrm{C}^{\prime}, 34 \mathrm{C}^{\prime}\right.$ and $\left.36 \mathrm{C}^{\prime}\right)$, the dimethylalkanes $\left(32 \mathrm{~B}^{\prime}, 33 \mathrm{~B}, 34 \mathrm{~B}^{\prime}\right.$ and $\left.35 \mathrm{~B}\right)$ and a $33 \mathrm{~A}$ methylalkane. After 3 additional days of adult development (day 7 diapause IP adults), the shift to longer carbon chain-length methylalkanes (C32-C37) was clearly apparent and the major component (peak) was a mixture of

Table 1

Percentage distribution for TAG of diapause IP and non-diapausing adults, 7 days postemergence.

\begin{tabular}{|c|c|c|}
\hline \multirow[t]{2}{*}{ TAG carbon number ${ }^{\mathrm{a}}$} & Diapause & Non-diapause \\
\hline & \multicolumn{2}{|c|}{ Percentage composition } \\
\hline 40 & $1.3 \pm 0.5$ & - \\
\hline 41 & - & - \\
\hline 42 & $2.1 \pm 0.9$ & $1.1 \pm 0.4$ \\
\hline 43 & - & - \\
\hline 44 & $1.9 \pm 0.5$ & $1.2 \pm 0.4$ \\
\hline 45 & $1.0 \pm 0.3$ & - \\
\hline 46 & $5.1 \pm 1.3$ & $1.7 \pm 0.2$ \\
\hline 47 & $1.0 \pm 0.3$ & - \\
\hline 48 & $5.4 \pm 1.2$ & $3.2 \pm 0.4$ \\
\hline 49 & $1.2 \pm 0.4$ & $2.1 \pm 0.3$ \\
\hline 50 & $12.6 \pm 1.3$ & $13.2 \pm 1.4$ \\
\hline 51 & $1.6 \pm 0.1$ & $5.4 \pm 0.6$ \\
\hline 52 & $32.8 \pm 3.6$ & $31.2 \pm 1.8$ \\
\hline 53 & $4.3 \pm 1.1$ & $8.0 \pm 1.4$ \\
\hline 54 & $22.6 \pm 3.6$ & $25.6 \pm 1.6$ \\
\hline 55 & $2.5 \pm 0.8$ & $3.7 \pm 1.7$ \\
\hline 56 & $3.7 \pm 0.9$ & $3.3 \pm 1.0$ \\
\hline
\end{tabular}

a The TAG carbon numbers represent the total number of carbons contained in the three fatty-acyl moieties of the glycerol ester molecules.

${ }^{b}$ For diapause and non-diapause adults, calculated values indicate the mean percentages and standard deviations (SD) for $n=5$ adults. three C34 trimethylalkane positional isomers (Table 2). After an additional 8 days of development (day 15 early diapause MP adults), GC-MS analyses of cuticular lipid extracts showed no change in the distribution of hydrocarbon components compared to day 7 adults (data not shown).

GC-MS peak areas for the cuticular hydrocarbon components were converted to $\mu \mathrm{g}$ amounts and total quantities were compared for diapause IP and early MP adults at 1, 4, 7, and 15 days after adult emergence (Fig. 5). The quantities increased steadily from an amount of $58 \mu \mathrm{g} /$ adult, for day 1 adults, $90 \mu \mathrm{g} /$ adult for day 4, to $110 \mu \mathrm{g} / \mathrm{adult}$ for day 7 diapause IP adults. Significantly, there was no increase in amounts of cuticular hydrocarbons for day 7 adults as compared to day 15 adults.

\subsection{Cuticular lipids of nondiapausing adults}

The chromatographic profiles of cuticular lipids of nondiapausing day 1 , day 4, and day 7 CPB adults showed the same methyl-branched components with very similar quantity distributions as determined for the diapause IP day 1, day 4, and day 7 and diapause MP adults (Fig. 4A, B and C and Table 2). The $\mu$ g/adult quantities for day 1, day 4, and day 7 non-diapause adults showed increases similar to the diapause IP adults (data not shown).

\section{Discussion}

For a variety of insect species, analyses of total lipid extracts have shown that the predominant lipid class is TAG (Downer, 1985) and that fat body tissues are the primary internal location of TAG storage (Downer, 1985; Keeley, 1985). Most insect species contain less than $10 \%$ of wet weight as lipid (Fast, 1966, 1970) and consistent with that level of stored lipid, the diapause-programmed CPB adults accumulate $6-7 \%$ of their wet weight as internal lipid by 15 days post-emergence. GC-MS analyses of the diapause and non-diapause CPB adult internal lipids revealed three major resolvable TAG peaks of 50, 52 and 54 total aryl carbons (see Fig. 1). The fatty acid moieties of these TAGs were identified as mixtures of saturated and unsaturated C16 and C18 fatty acids: a common occurrence for TAGs of most insect species (Downer, 1985; Stanley-Samuelson et al., 1988). The TAG composition from both diapause and non-diapause adult CPB consisted of lesser, but prominent, quantities of odd carbon number TAGs (Table 1). GC-MS analyses revealed that the odd-chain fatty acid moieties were the C15 


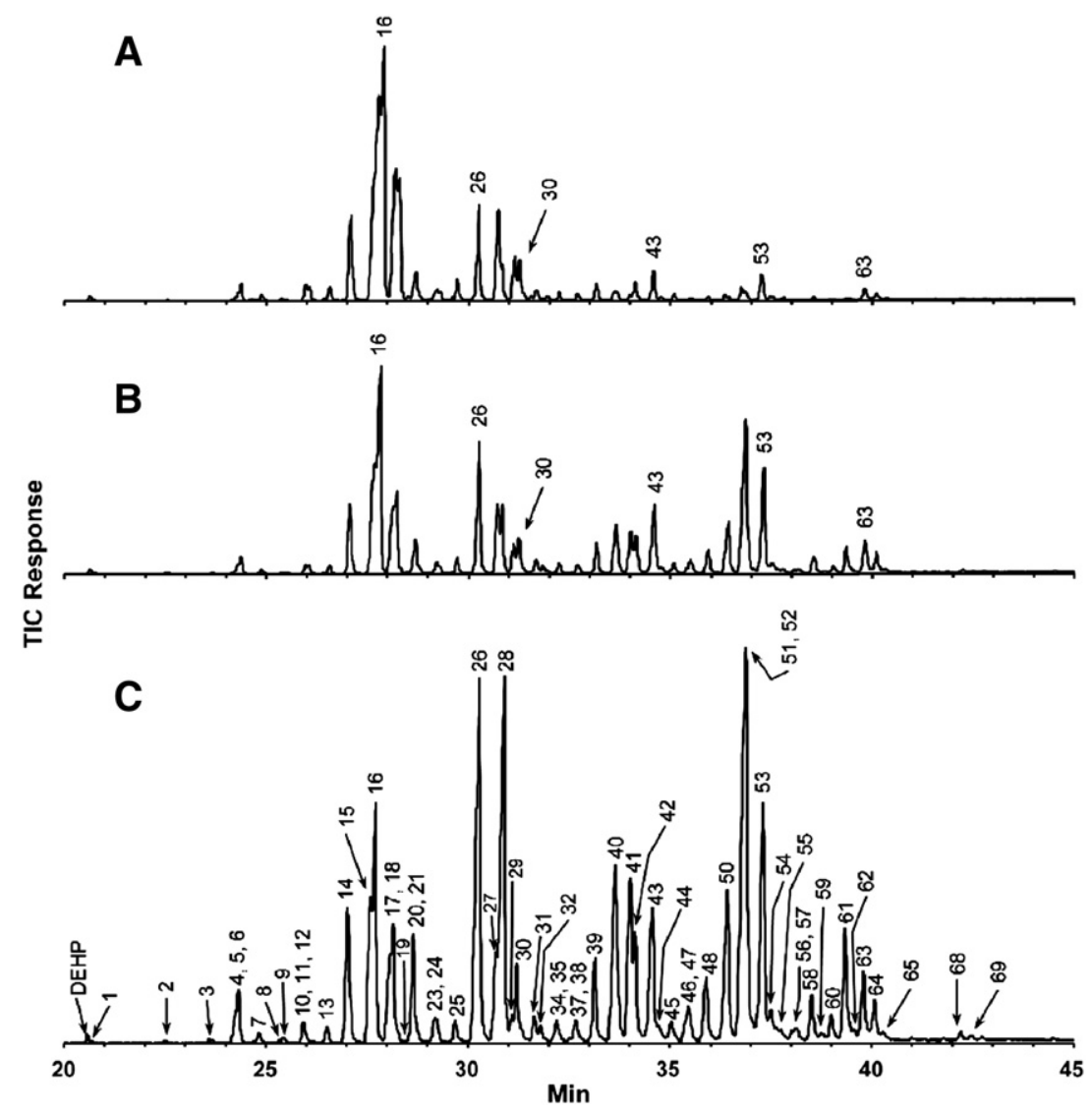

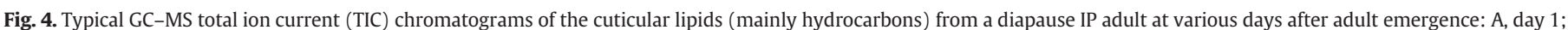

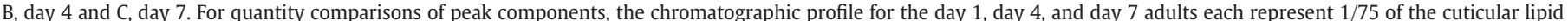

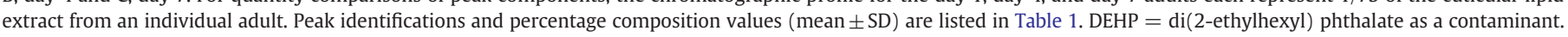

and C17 fatty acids. The occurrence of odd carbon fatty acids in insects arises from utilization of three-carbon propionyl-CoA as the starter compound instead of two-carbon acetyl-CoA during the initial steps of fatty acid biosynthesis (Stanley-Samuelson et al., 1988). These acquired quantities of stored lipid are important to sustain CPB adults during the overwintering periods of diapause and reduced metabolic activity, and is consistent with the argument (Downer, 1985) that stored TAGs are frequently associated with species that undergo lengthy periods of metabolic activity (i.e., diapause or migratory flight) or that have non-feeding stages of development (e.g., pupa and adult).

Methyl-branched hydrocarbons have been identified as cuticular components in many species of insects (Blomquist et al., 1987; Lockey, 1988; Nelson, 1993; Nelson and Blomquist, 1995; Blomquist, 2010a). For the Colorado potato beetle, methyl-branched hydrocarbons were shown to be the major components in cuticular lipid extracts (Maliński et al., 1986; Dubis et al., 1987; Szafranek et al., 1994; Nelson et al., 2003). The composition of methyl-branched hydrocarbons that we have determined for adult diapause IP and MP CPB adults (Fig. 4 and Table 2) is very similar to the distribution of methyl-branched hydrocarbons previously reported for nondiapausing male and female CPB (Nelson et al., 2003). They reported that the CPB is unique in that a majority of the hydrocarbons had a methyl branch on carbon 2: $52.9 \%$ of total lipid composition in the adult males and $65.1 \%$ in the adult females. Similarly, for the mixed sex CPB in our study, methyl-branched alkanes with a methyl branch on the carbon 2 position were identified in the majority of hydrocarbons of day 1 , day 4, and day 7 diapausing IP adults: $74.8 \%, 68.5 \%$ and $69.0 \%$, respectively (Table 2) and similar percentages for the hydrocarbons of day 1, day 4 , and day 7 nondiapausing adults (data not shown). The occurrence of large quantities of 2-methylalkanes in CPB cuticular lipid probably results from the biosynthetic utilization of branched amino acids as the direct source of the methyl branch of the 2-methylalkanes (Nelson, 1993; Blomquist, 2010b). The carbon skeleton of valine (to initiate chain synthesis) leads to even-numbered carbons in the backbone and the carbon skeleton of leucine leads to odd-numbered carbons in the hydrocarbon backbone.

For several lepidopteran species, diapausing pupae deposit substantially more lipid on their cuticular surface than nondiapausing pupae (Bell et al., 1975; Hegdekar, 1979; Buckner et al., 1984a,b, 1996). In our present study, the amounts of lipid on the cuticular surfaces of adult CPB in diapause IP were not larger than for nondiapausing adults, and actually, the nondiapausing adults at 1, 4 and 7 days after adult emergence had slightly higher quantities of cuticular hydrocarbons than their diapause IP counterparts. Our GCMS analyses (Fig. 4 and Table 2) showed accumulations of longer chain-length methyl-branched alkanes (C32-C37) at the later stages of the diapause initiation phase. The overall increases in hydrocarbon chain length should provide CPB adults with a more "waxy" cuticular surface and an improved ability to avoid loss of water during times of overwintering.

Diapause is a developmental pathway with distinct phases (Koštál, 2006); the challenge in achieving a holistic view of diapause is the development of reliable biomarkers to further define these phases. The diapause IP of the CPB is characterized by a specific sequence of physiological events. The respiration pattern of adults in the diapause IP forms an inverted " $U$ " with peak activity between days 4 and 7 postemergence and it reaches its lowest level as the beetles enter the diapause MP on day 15 (Yocum et al., 2009a). The diapause IP can also be subdivided by the timing of specific gene expression (de Kort and Koopmanschap, 1994; de Kort, 1996; Yocum, 2003; Yocum et al., 2009a,b). As with respiration and gene expression, lipid metabolism 
Table 2

Percentage composition (mean \pm SD) of the hydrocarbons in the cuticular lipids of diapausing Colorado potato beetles at days $1,4,7$ and 15 after adult emergence.

\begin{tabular}{|c|c|c|c|c|c|c|}
\hline \multirow[t]{2}{*}{ Peak number ${ }^{\mathrm{b}}$} & \multirow[t]{2}{*}{ GC-MS component ${ }^{\mathrm{C}}$} & \multicolumn{4}{|c|}{ Percentage composition $^{\mathrm{a}}$} & \multirow[t]{2}{*}{ Scientific name ${ }^{d}$} \\
\hline & & Day 1 & Day 4 & Day 7 & Day 15 & \\
\hline 1 & 25 & & $0.1 \pm 0.0$ & $0.1 \pm 0.0$ & $0.1 \pm 0.0$ & $n$-Pentacosane \\
\hline 2 & 26 & $\mathrm{t}$ & $0.1 \pm 0.0$ & $0.1 \pm 0.0$ & $0.1 \pm 0.0$ & $n$-Hexacosane \\
\hline 3 & $26 A^{\prime}$ & $\mathrm{t}$ & $0.1 \pm 0.0$ & $0.1 \pm 0.0$ & $0.1 \pm 0.0$ & 2-Methylhexacosane \\
\hline 4 & 27 & & & $0.3 \pm 0.2$ & $0.1 \pm 0.1$ & $n$-Heptacosane \\
\hline 5 & $26 \mathrm{~B}^{\prime}$ & $0.5 \pm 0.3$ & $0.5 \pm 0.2$ & $0.3 \pm 0.1$ & $0.1 \pm 0.1$ & 2,10-, 2,12-, 2,8-Dimethylhexacosanes \\
\hline 6 & $26 B^{\prime}$ & $0.8 \pm 0.5$ & $0.9 \pm 0.3$ & $0.8 \pm 0.3$ & $0.4 \pm 0.3$ & 2,6-Dimethylhexacosane \\
\hline 7 & $26 C^{\prime} ?, 27 A ?$ & $0.6 \pm 0.3$ & $0.5 \pm 0.2$ & $0.3 \pm 0.2$ & $0.2 \pm 0.1$ & \\
\hline 8 & $27 A^{\prime}$ & $0.2 \pm 0.0$ & $0.1 \pm 0.0$ & $0.1 \pm 0.0$ & $0.1 \pm 0.0$ & 3-Methylheptacosane \\
\hline 9 & 27B & $0.1 \pm 0.0$ & $0.1 \pm 0.0$ & $0.1 \pm 0.1$ & $0.1 \pm 0.0$ & 9,17-, 11,17-Dimethylheptacosanes \\
\hline 10 & $27 \mathrm{~B}^{\prime}$ & $0.7 \pm 0.1$ & $0.4 \pm 0.1$ & $0.2 \pm 0.1$ & $0.1 \pm 0.0$ & 2,17-Dimethylheptacosane \\
\hline 11 & 28 & & & $0.1 \pm 0.1$ & $0.1 \pm 0.1$ & n-Octacosane \\
\hline 12 & $27 \mathrm{~B}^{\prime}$ & $0.7 \pm 0.1$ & $0.4 \pm 0.1$ & $0.3 \pm 0.1$ & $0.2 \pm 0.1$ & 2,21-Dimethylheptacosane \\
\hline 13 & $28 \mathrm{~A}$ & $1.2 \pm 0.2$ & $0.6 \pm 0.1$ & $0.4 \pm 0.1$ & $0.3 \pm 0.1$ & 10-Methyloctacosane \\
\hline 14 & $28 \mathrm{~A}^{\prime}$ & $5.9 \pm 0.9$ & $4.3 \pm 0.9$ & $4.3 \pm 0.8$ & $3.1 \pm 0.8$ & 2-Methyloctacosane \\
\hline 15 & $28 \mathrm{~B}^{\prime}$ & $22.8 \pm 3.3$ & $10.3 \pm 2.6$ & $6.0 \pm 2.0$ & $4.2 \pm 1.1$ & 2,17-Dimethyloctacosane \\
\hline 16 & $28 \mathrm{~B}^{\prime}$ & $11.5 \pm 1.7$ & $8.0 \pm 1.5$ & $8.0 \pm 1.9$ & $6.0 \pm 1.3$ & 2,6-Dimethyloctacosane \\
\hline 17 & $28 C^{\prime}$ & $9.0 \pm 1.5$ & $5.7 \pm 2.1$ & $3.8 \pm 1.2$ & $3.1 \pm 0.6$ & 2,10,18-, 2,10,16-Trimethyloctacosanes \\
\hline 18 & $29 \mathrm{~A}$ & $5.1 \pm 0.4$ & $2.5 \pm 0.6$ & $2.0 \pm 0.4$ & $1.6 \pm 0.2$ & 11-Methylnonacosane \\
\hline 19 & $29 A^{\prime} 2-$ & $0.2 \pm 0.0$ & $0.2 \pm 0.1$ & $0.1 \pm 0.0$ & $0.1 \pm 0.1$ & 2-Methylnonacosane \\
\hline 20 & $29 B$ & $2.9 \pm 0.4$ & $2.7 \pm 0.5$ & $2.4 \pm 0.7$ & $2.5 \pm 0.6$ & 11,19-Dimethylnonacosane \\
\hline 21 & $29 A^{\prime} 3-$ & $0.2 \pm 0.1$ & $0.2 \pm 0.2$ & $0.2 \pm 0.1$ & $0.2 \pm 0.0$ & 3-Methylnonacosane \\
\hline 22 & $29 \mathrm{~B}^{\prime}$ & $0.0 \pm 0.0$ & $0.0 \pm 0.0$ & $0.0 \pm 0.0$ & $0.2 \pm 0.1$ & 2,19-, 2,17-Dimethylnonacosanes \\
\hline 23 & 30 & $0.8 \pm 0.1$ & $0.5 \pm 0.1$ & $0.4 \pm 0.1$ & $0.4 \pm 0.2$ & $n$-Triacontane \\
\hline 24 & $29 \mathrm{~B}^{\prime}$ & $0.5 \pm 0.0$ & $0.4 \pm 0.1$ & $0.3 \pm 0.1$ & $0.3 \pm 0.1$ & 2,23-Dimethylnonacosane \\
\hline 25 & $30 \mathrm{~A}$ & $1.6 \pm 0.2$ & $1.0 \pm 0.2$ & $0.7 \pm 0.2$ & $0.7 \pm 0.1$ & 12-Methyltriacontane \\
\hline 26 & $30 A^{\prime}$ & $5.5 \pm 1.4$ & $7.0 \pm 0.6$ & $8.0 \pm 1.4$ & $10.0 \pm 0.6$ & 3-Methyltriacontane \\
\hline 27 & $30 \mathrm{~B}^{\prime}$ & $5.8 \pm 0.5$ & $3.9 \pm 0.7$ & $3.3 \pm 0.9$ & $3.3 \pm 0.6$ & 2,12-, 2,10-Dimethyltriacontanes \\
\hline 28 & $30 \mathrm{~B}^{\prime}$ & $1.5 \pm 0.5$ & $3.1 \pm 1.9$ & $4.0 \pm 2.6$ & $3.8 \pm 1.0$ & 2,6-, 2,4-Dimethyltriacontanes \\
\hline 29 & $30 C^{\prime}$ & $2.7 \pm 0.5$ & $1.5 \pm 0.4$ & $1.2 \pm 0.4$ & $1.1 \pm 0.3$ & $2,10,18-, 2,10,20-, 2,12,18$-Trimethyltriacontanes \\
\hline 30 & $31 \mathrm{~A}$ & $2.2 \pm 0.3$ & $1.9 \pm 0.2$ & $1.7 \pm 0.2$ & $1.9 \pm 0.2$ & 13-Methylhentriacontane \\
\hline 31 & $31 \mathrm{~B}$ & $0.9 \pm 0.2$ & $0.9 \pm 0.2$ & $0.7 \pm 0.1$ & $0.8 \pm 0.1$ & 11,17-, 11,19-, 7,11-Dimethylhentriacontanes \\
\hline 32 & $31 \mathrm{~A}^{\prime}$ & $0.2 \pm 0.1$ & $0.4 \pm 0.1$ & $0.5 \pm 0.1$ & $0.4 \pm 0.1$ & 2-Methylhentriacontane \\
\hline 33 & $?$ & $0.3 \pm 0.1$ & $0.2 \pm 0.1$ & & & \\
\hline 34 & $31 \mathrm{~B}^{\prime}$ & $0.6 \pm 0.1$ & $0.6 \pm 0.1$ & $0.3 \pm 0.1$ & $0.2 \pm 0.1$ & 2,21-, 2,19-, and 2,15-Dimethylhentriacontanes \\
\hline 35 & 32 & & & $0.2 \pm 0.2$ & $0.2 \pm 0.2$ & $n$-Dotriacontane \\
\hline 36 & $31 \mathrm{~B}^{\prime}$ & & & & $0.2 \pm 0.0$ & 2,25-Dimethylhentriacontane \\
\hline 37 & $31 C^{\prime}$ & $0.3 \pm 0.1$ & $0.2 \pm 0.1$ & $0.1 \pm 0.0$ & $0.1 \pm 0.0$ & 2,15,21-Trimethylhentriacontane \\
\hline 38 & $32 \mathrm{~A}$ & $0.2 \pm 0.1$ & $0.6 \pm 0.1$ & $0.7 \pm 0.2$ & $0.7 \pm 0.1$ & 10-, 12-Methyldotriacontanes \\
\hline 39 & $32 \mathrm{~A}^{\prime}$ & $1.0 \pm 0.2$ & $1.3 \pm 0.1$ & $1.3 \pm 0.1$ & $1.6 \pm 0.2$ & 2-Methyldotriacontane \\
\hline 40 & $32 \mathrm{~B}^{\prime}$ & $1.0 \pm 0.2$ & $3.1 \pm 0.7$ & $4.0 \pm 0.9$ & $4.1 \pm 0.9$ & 2,10, 2,12-Dimethyldotriacontanes \\
\hline 41 & $32 C^{\prime}$ & $0.5 \pm 0.2$ & $2.1 \pm 0.4$ & $4.0 \pm 0.7$ & $4.6 \pm 1.4$ & 2,10,16-Trimethyldotriacontane \\
\hline 42 & $33 \mathrm{~A}$ & $1.0 \pm 0.2$ & $1.8 \pm 0.2$ & $1.7 \pm 0.2$ & $2.0 \pm 0.2$ & 13-Methyltritriacontane \\
\hline 43 & $33 \mathrm{~B}$ & $1.9 \pm 0.4$ & $3.4 \pm 0.3$ & $3.2 \pm 0.3$ & $3.7 \pm 0.6$ & 11,17-Dimethyltritriacontane \\
\hline 44 & $33 C$ & $0.4 \pm 0.1$ & $0.5 \pm 0.1$ & $0.4 \pm 0.1$ & $0.4 \pm 0.1$ & 13,17,21-Trimethyltritriacontane \\
\hline 45 & $33 \mathrm{~B}^{\prime}$ & $0.4 \pm 0.1$ & $0.5 \pm 0.1$ & $0.4 \pm 0.1$ & $0.5 \pm 0.1$ & 2,23-, 2,17-Dimethyltritriacontanes \\
\hline 46 & $33 C^{\prime}$ & & $0.2 \pm 0.1$ & $0.3 \pm 0.1$ & $0.3 \pm 0.1$ & 2,17,23-Trimethyltritriacontane \\
\hline 47 & $34 \mathrm{~A}$ & $0.2 \pm 0.0$ & $0.7 \pm 0.1$ & $0.7 \pm 0.2$ & $0.9 \pm 0.2$ & 17-Methyltetratriacontane \\
\hline 48 & $34 \mathrm{~B}$ & $0.3 \pm 0.1$ & $1.1 \pm 0.2$ & $1.5 \pm 0.3$ & $2.1 \pm 0.4$ & 10,18-, 12,18-Dimethyltetratriacontanes \\
\hline 49 & $34 C$ & $0.2 \pm 0.1$ & & & & \\
\hline 50 & $34 \mathrm{~B}^{\prime}$ & $0.2 \pm 0.1$ & $2.6 \pm 0.6$ & $3.1 \pm 0.6$ & $2.9 \pm 0.5$ & 2,16-, 2,10-Dimethyltetratriacontanes \\
\hline 51 & $34 C^{\prime}$ & $0.9 \pm 0.4$ & $8.1 \pm 1.0$ & $11.3 \pm 1.1$ & $11.4 \pm 1.2$ & 2,10,16-, 2,12,18-, 2,10,18-Trimethyltetratriacontanes \\
\hline 52 & $35 \mathrm{~A}$ & $0.5 \pm 0.1$ & $1.1 \pm 0.3$ & $1.1 \pm 0.2$ & $1.5 \pm 0.4$ & 13-, 15,-, 17-Methylpentatriacontanes \\
\hline 53 & $35 \mathrm{~B}$ & $1.6 \pm 0.3$ & $5.0 \pm 0.5$ & $5.4 \pm 0.6$ & $5.8 \pm 1.6$ & 13,19-, 11,17-, 11,23-Dimethylpentatriacontanes \\
\hline 54 & $35 \mathrm{C}$ & $0.6 \pm 0.2$ & $0.7 \pm 0.1$ & $0.8 \pm 0.1$ & $0.9 \pm 0.2$ & 13,17,23-, 11,15,23-Trimethylpentatriacontanes \\
\hline 55 & $35 \mathrm{~B}^{\prime}$ & $0.2 \pm 0.0$ & $0.3 \pm 0.1$ & $0.3 \pm 0.1$ & $0.3 \pm 0.1$ & \\
\hline 56 & $35 C^{\prime}$ & $\mathrm{t}$ & $0.1 \pm 0.0$ & $0.1 \pm 0.1$ & $0.2 \pm 0.1$ & 2,17,25-Trimethylpentatriacontane \\
\hline 57 & $36 \mathrm{~A}$ & $0.1 \pm 0.0$ & $0.3 \pm 0.0$ & $0.3 \pm 0.1$ & $0.5 \pm 0.2$ & 13-, 15-, 17-, 18-Methylhexatriacontanes \\
\hline 58 & $36 \mathrm{~B}$ & $0.2 \pm 0.0$ & $0.9 \pm 0.2$ & $1.0 \pm 0.2$ & $1.4 \pm 0.4$ & 12,16-, 12,18-, 12,20-, 10,18-, 13,??-Dimethylhexatriacontanes \\
\hline 59 & $36 C$ & $0.1 \pm 0.0$ & $0.1 \pm 0.0$ & $0.2 \pm 0.0$ & $0.3 \pm 0.1$ & $12,16,20-, 10,14,18$-Trimethylhexatriacontanes \\
\hline 60 & $36 \mathrm{~B}^{\prime}$ & $0.1 \pm 0.1$ & $0.4 \pm 0.1$ & $0.4 \pm 0.1$ & $0.6 \pm 0.1$ & 2,10-, 2,20-, 2,18-Dimethylhexatriacontanes \\
\hline 61 & $36 C^{\prime}$ & $0.1 \pm 0.1$ & $1.3 \pm 0.5$ & $1.6 \pm 0.6$ & $1.8 \pm 0.5$ & 2,10,18-Trimethylhexatriacontane \\
\hline 62 & $37 \mathrm{~A}$ & $0.2 \pm 0.1$ & $0.2 \pm 0.1$ & $0.2 \pm 0.1$ & $0.4 \pm 0.3$ & 13-, 15-, 17-, 19-Methylheptatriacontanes \\
\hline 63 & $37 \mathrm{~B}$ & $0.9 \pm 0.2$ & $1.9 \pm 0.4$ & $1.7 \pm 0.5$ & $1.8 \pm 0.4$ & 13,25-Dimethylheptatriacontane \\
\hline 64 & $37 C$ & $0.8 \pm 0.2$ & $1.0 \pm 0.3$ & $1.1 \pm 0.3$ & $1.5 \pm 0.5$ & 13,17,25-Trimethylheptatriacontane \\
\hline 65 & $37 \mathrm{D}$ & $0.2 \pm 0.0$ & $0.2 \pm 0.1$ & $0.3 \pm 0.1$ & $0.2 \pm 0.1$ & $13,17,21,25$-Tetramethylheptatriacontane \\
\hline 66 & $38 \mathrm{~B}$ & & & & $0.1 \pm 0.0$ & 10,18-, 12,16-, 12,18-, 12,20-Dimethyloctatriacontanes \\
\hline 67 & $38 \mathrm{C}$ & & & & $0.1 \pm 0.0$ & 13,17,21-Trimethyloctatriacontane \\
\hline 68 & $39 \mathrm{~B}$ & $0.2 \pm 0.0$ & $0.3 \pm 0.1$ & $0.2 \pm 0.1$ & $0.2 \pm 0.1$ & 13,25-, 13,23-, 13,19-Dimethylnonatriacontanes \\
\hline 69 & $39 C$ & $0.1 \pm 0.0$ & $0.2 \pm 0.1$ & $0.2 \pm 0.0$ & $0.2 \pm 0.1$ & 13,17,25-, 13,19,25-Trimethylnonatriacontanes \\
\hline 70 & $51 \mathrm{~B}$ & $0.1 \pm 0.0$ & $0.1 \pm 0.0$ & $0.2 \pm 0.1$ & $0.1 \pm 0.0$ & 13,23-, 13,21-Dimethylhenpentacontanes \\
\hline 71 & $51 C$ & $0.1 \pm 0.1$ & $0.2 \pm 0.0$ & $0.3 \pm 0.1$ & $0.2 \pm 0.1$ & 13,21,25-Trimethylhenpentacontane \\
\hline 72 & $53 \mathrm{~B}$ & $0.1 \pm 0.1$ & $0.1 \pm 0.0$ & $0.1 \pm 0.1$ & $0.2 \pm 0.1$ & 13,21-Dimethyltripentacontane \\
\hline 73 & $53 \mathrm{C}$ & $0.2 \pm 0.1$ & $0.3 \pm 0.1$ & $0.3 \pm 0.1$ & $0.4 \pm 0.2$ & $13,21,27-, 13,21,25$-Trimethyltripentacontanes \\
\hline
\end{tabular}




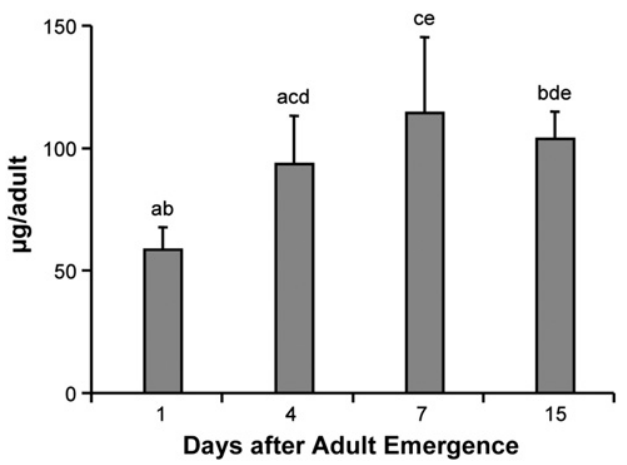

Fig. 5. Quantities of cuticular lipids (mainly hydrocarbons) for diapause IP and diapause MP adults at various days post-emergence. Quantities ( $\mu \mathrm{g})$ were determined from the total ion current (TIC) peak areas for the GC-MS analysis of cuticular lipids for individual adults. Conversions of peak areas to $\mu$ g quantities were made by using slope data for increasing amounts of authentic hydrocarbon standards. The height of each bar indicates the mean $\mu \mathrm{g} /$ insect values for $n=7$ adults and standard deviation (SD) is indicated by the error bars. Bars with the same letters are not significantly different (one way ANOVA, $P>0.05$ ).

can also serve as a biomarker to clarify developmental milestones during CPB diapause IP. Day 1 post-emergence beetles possess only trace amounts of lipids. Lipid titer increases slowly until day 7 after which approximately $80 \%$ of the lipids needed for overwintering are stockpiled. Fink (1925) demonstrated a similar rapid increase in lipids prior to the beetles entering diapause, though his undefined time interval makes it difficult to make an accurate comparison. It is interesting that the period of peak lipid accumulation (days 7 to 15) in $\mathrm{CPB}$ coincides with the period of decreasing metabolic rates (days 7 to 15 ) as measured by respiration (Yocum et al., 2009a). In conclusion, no major quantitative or qualitative differences between diapause or nondiapause adult beetles were found. This suggests that as it relates to lipid metabolism the decision to enter diapause or not, only controls the final allocation of lipids either into metabolic reserves for diapause or into reproduction for nondiapausing beetles.

\section{Acknowledgments}

We thank Marnie Larson for technical assistance, Bonnie Muhl for data presentation and figure preparations, and Drs. Heldur Hakk and Joseph Rinehart for critical reviews of the manuscript.

\section{References}

Bell, R.A., Nelson, D.R., Borg, T.K., Cardwell, D.L., 1975. Wax secretion in non-diapause and diapausing pupae of the tobacco hornworm, Manduca sexta. J. Insect Physiol. $21,1725-1729$.

Blomquist, G.J., 2010a. Structure and analysis of insect hydrocarbons. In: Blomquist, G.J., Bagneres, A.-G. (Eds.), Insect Hydrocarbons: Biology, Biochemistry, and Chemical Ecology. Cambridge University Press, New York, NY, pp. 19-34.

Blomquist, G.J., 2010b. Biosynthesis of cuticular hydrocarbons. In: Blomquist, G.J. Bagneres, A.-G. (Eds.), Insect Hydrocarbons: Biology, Biochemistry, and Chemical Ecology. Cambridge University Press, New York, NY, pp. 35-52.

Blomquist, G.J., Nelson, D.R., de Renobales, M., 1987. Chemistry, biochemistry and physiology of insect cuticular lipids. Arch. Insect Biochem. Physiol. 6, 227-265.

Buckner, J.S., 1993. Polar cuticular lipids. In: Stanley-Samuelson, D.W., Nelson, D.R. (Eds.), Insect Lipids: Chemistry, Biochemistry and Biology. University of Nebraska Press, Lincoln, pp. 227-270.

Buckner, J.S., Nelson, D.N., Hakk, H., Pomonis, J.G., 1984a. Long chain oxoaldehydes and oxoalcohols from esters as major constituents of the surface lipids of Manduca sexta pupae in diapause. J. Biol. Chem. 259, 8452-8460.
Buckner, J.S., Nelson, D.N., Fatland, C.L., Hakk, H., Pomonis, J.G., 1984b. Novel surface lipids of diapausing Manduca sexta pupae: long chain oxoalcohol esters of acetoacetic, hydroxybutyric, and acetic acids. J. Biol. Chem. 259, 8461-8470.

Buckner, J.S., Mardaus, M.C., Nelson, D.N., 1996. Cuticular lipid composition of Heliothis virescens and Helicoverpa zea pupae. Comp. Biochem. Physiol. B 114, 207-216.

Buckner, J.S., Kemp, W.P., Bosch, J., 2004. Characterization of triacylglycerols from overwintering prepupae of the alfalfa pollinator Megachile rotundata (Hymenoptera: Megachilidae). Arch. Insect Biochem. Physiol. 57, 1-14.

Carlson, D.A., Bernier, U.R., Sutton, B.D., 1998. Elution patterns from capillary GC for methyl-branched alkanes. J. Chem. Ecol. 24, 1845-1865.

Casagrande, R.A., 1985. The "Iowa" potato beetle, its discovery and spread to potatoes. Bull. Entomol. Soc. Am. 31, 27-29.

Casagrande, R.A., 1987. The Colorado potato beetle: 125 years of mismanagement. Bull. Entomol. Soc. Am. 33, 142-150.

Chirumamilla, A. Buckner, J.S., Yocum, G.D., Fatland, C.L., Boetel, M.B., 2010. Internal lipids of sugarbeet root maggot (Tetanops myopaeformis) larvae: effects of multiyear cold storage. Comp. Biochem. Physiol. B 157, 73-79.

Clark, J.F.M., 2007. "The eyes of our potatoes are weeping": the rise of the Colorado beetle as an insect pest. Arch. Nat. Hist. 43, 109-128.

Danks, H.V., 1987. Insect Dormancy: An Ecological Perspective. Biological Survey of Canada, Ottawa, Ontario.

Danks, H.V., 2000. Dehydration in dormant insects. J. Insect Physiol. 46, 837-852.

de Kort, C.A.D., 1990. Thirty-five years of diapause research with the Colorado potato beetle. Entomol. Exp. Appl. 56, 1-14.

de Kort, C.A.D., 1996. Cosmic influences on the expression of a specific gene in the Colorado potato beetle: the diapause protein 1 gene. Arch. Insect Biochem. Physiol. 32, 567-573.

de Kort, C.A.D., Koopmanschap, A.B., 1994. Nucleotide and deduced amino acid sequence of a cDNA clone encoding diapause protein 1, an arylphorin-type storage hexamer of the Colorado potato beetle. J. Insect Physiol. 40, 527-535.

Downer, R.G.H., 1985. Lipid metabolism. In: Kerkut, G.A., Gilbert, L.I. (Eds.), Comprehensive Insect Physiology, Biochemistry and Pharmacology. Pergamon Press, Oxford, pp. 77-113.

Dubis, E., Maliński, E., Dubis, A., Szafranek, J., Nawrot, J., Popławski, J., Wróbel, J.T., 1987. Sex-dependent composition of cuticular hydrocarbons of the Colorado beetle, Leptinotarsa decemlineata Say. Comp. Biochem. Physiol. A 87, 839-843.

EPPO, 2006. Distribution maps of quarantine pests for Europe, Leptinotarsa decemlineata. http://pqr.eppo.org/datas/LPTNDE/LPTNDE.pdf.

Fast, P.G., 1966. A comparative study of the phospholipids and fatty acids of some insects. Lipids 1, 209-215.

Fast, P.G., 1970. Insect lipids. In: Holman, R.T. (Ed.), Progress in the Chemistry of Fats and Other Lipids, vol. 11. Pergamon Press, Oxford, pp. 181-242.

Ferro, D.N., 1985. Pest status and control strategies of the Colorado potato beetle. In: Ferro, D.N., Voss, R.N. (Eds.), Proceedings of the Symposium on the Colorado Potato Beetle, 17th International Congress of Entomology: Massachusetts Agricultural Experimental Station Research Bulletin, 704, pp. 1-8.

Fink, D.E., 1925. Physiological studies on hibernation in the potato beetle, Leptinotarsa decemlineata Say. Biol. Bull. 49, 381-406.

Gauthier, N.L., Hofmaster, R.N., Semal, M., 1981. History of Colorado potato beetle control. In: Lashomb, J.H., Casagrande, R.A. (Eds.), Advances in Potato Pest Management. Hutchinson Ross, Stroudsburg, PA, pp. 13-33.

Hahn, D.A., Denlinger, D.L., 2007. Meeting the energetic demands of insect diapause: nutrient storage and utilization. J. Insect Physiol. 53, 760-773.

Hegdekar, B.M., 1979. Epicuticular wax secretion in diapause and non-diapause pupae of the bertha armyworm. Ann. Entomol. Soc. Am. 72, 13-15.

Keeley, L.L., 1985. Physiology and biochemistry of the fat body. In: Kerkut, G.A., Gilbert, L.I. (Eds.), Comprehensive Insect Physiology, Biochemistry and Pharmacology. Pergamon Press, Oxford, pp. 211-248.

Koštál, V., 2006. Eco-physiological phases of insect diapause. J. Insect Physiol. 52, $113-127$.

Lefevere, K.S., Koopmanschap, A.B., de Kort, C.A.D., 1989. Changes in the concentration of metabolites in haemolymph during and after diapause in female Colorado potato beetle, Leptinotarsa decemlineata. J. Insect Physiol. 35, 121-128.

Lockey, K.H., 1988. Review-lipids of the insect cuticle: origin, composition and function. Comp. Biochem. Physiol. B 89, 595-645.

Maliński, E., Kusmierz, J., Szafranek, J., et al., 1986. Cuticular hydrocarbons of the Colorado beetle Leptinotarsa decemlineata Say. Z. Naturforsch. Part B 41, 567-574.

Nelson, D.R., 1993. Methyl-branched lipids in insects. In: Stanley-Samuelson, D.W. Nelson, D.R. (Eds.), Insect Lipids: Chemistry, Biochemistry, and Biology. University of Nebraska Press, Lincoln, NE, pp. 271-315.

Nelson, D.R., Blomquist, G.J., 1995. Insect waxes. In: Hamilton, R.J., Christie, W.W. (Eds.), Waxes: Chemistry, Molecular Biology and Functions. The Oily Press, Ltd, Dundee, Scotland, pp. 1-90. Chapter 1.

Nelson, D.R., Adams, T.S., Fatland, C.L., 2003. Hydrocarbons in the surface wax of eggs and adults of the Colorado potato beetle, Leptinotarsa decemlineata. Comp. Biochem. Physiol. B 134, 447-466.

\footnotetext{
Notes to Table 2:

a Percent compositions for adults 1, 4, 7 and 15 days after adult emergence were calculated as mean \pm SD values $(n=5)$; $t=$ trace amount ( mean $<0.1)$.

b Peak number assignment as shown in Fig. 4.

c The GC-MS component numbers for each peak indicate the number of carbon atoms in the backbone of the hydrocarbon molecule; the letters indicate the number of methyl

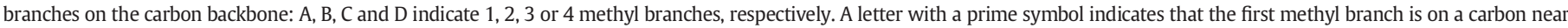
the end of the carbon chain backbone, i.e. on carbon 2 or 3 .

d Scientific names for peak numbers with multiple positional isomer components are listed in order of abundance.
} 
Petrova, D.V., 1976. Effect of ecological conditions of hibernation on gas exchange and some indices of energy balance in the Colorado beetle. In: Arnoldi, K.V. (Ed.), Ecology and Physiology of Diapause in the Colorado Beetle. Izdatel'stvo "Nauka", Moscow (English translation, Indian National Documentation Centre, New Delhi, 1976).

Stanley-Samuelson, D.W., Jurenka, R.A., Cripps, C., Blomquist, G.J., deRenobales, M., 1988. Fatty acids in insects: composition, metabolism and biological significance. Arch. Insect Biochem. Physiol. 9, 1-33.

Szafranek, J., Maliński, E., Dubis, E., et al., 1994. Identification of branched alkanes in lipids of Leptinotarsa decemlineata Say and Tribolium destructor by GC-MS: a comparison of main-beam and link-scanned spectra. J. Chem. Ecol. 20, 2197-2212.

Tauber, M.J., Tauber, C.A., Masaki, S., 1986. Seasonal Adaptations in Insects. Oxford Press, Oxford.

Tower, W.L., 1906. An investigation of evolution in chrysomelid beetles of the genus Leptinotarsa. Carnegie Institution of Washington, Washington, DC. pp. 12, 25-27, 250.

Tower, W.L., 1918. The Mechanism of Evolution in Leptinotarsa. Carnegie Institution of Washington, Washington, DC, p. 367.
Weber, D.C., Ferro, D.N., 1994. Colorado potato beetle: diverse life history poses challenge to management. In: Zehnder, G.W., Powelson, M.L., Jansson, R.K., Raman, K.V. (Eds.), Advances in Potato Pest Biology and Management. APS Press, St. Paul Minnesota, pp. 54-70.

Wharton, G.W., 1985. Water balance in insects. In: Gilbert, L.I., Iatrou, K., Gill, S.S. (Eds.) Comprehensive Molecular Insect Science, vol. 4. Elsevier, Amsterdam, pp. 565-601.

Yocum, G.D., 2003. Isolation and characterization of three diapause-associated transcripts from the Colorado potato beetle, Leptinotarsa decemlineata. J. Insect Physiol. 49, 161-169.

Yocum, G.D., Rinehart, J.P., Chirumamilla-Chapara, A., Larson, M.L., 2009a. Characterization of gene expression patterns during the initiation and maintenance phases of diapause in the Colorado potato beetle, Leptinotarsa decemlineata. J. Insect Physiol. $55,32-39$.

Yocum, G.D., Rinehart, J.P., Larson, M.L., 2009b. Down-regulation of gene expression between the diapause initiation and maintenance phases of the Colorado potato beetle, Leptinotarsa decemlineata. Eur. J. Entomol. 106, 471-476. 